\title{
Perceived and content-related emotional demands at work and risk of long-term sickness absence in the Danish workforce: a cohort study of 26410 Danish employees
}

\author{
Elisabeth Framke ๑๑ , ${ }^{1}$ Jeppe Karl Sørensen, ${ }^{1}$ Mads Nordentoft, ${ }^{1}$ Nina Føns Johnsen, ${ }^{1}$

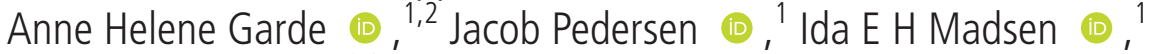 \\ Reiner Rugulies
}

- Additional material is published online only. To view please visit the journal online (http://dx.doi.org/10.1136/ oemed-2019-106015).

${ }^{1}$ National Research Centre for the Working Environment, Copenhagen, Denmark 2Department of Public Health, University of Copenhagen Copenhagen, Denmark ${ }^{3}$ Department of Psychology, University of Copenhagen, Copenhagen, Denmark

Correspondence to Dr Elisabeth Framke, National Research Centre for the Working Environment, Copenhagen, Denmark; elf@nfa.dk

Received 7 June 2019 Revised 26 September 2019 Accepted 4 October 2019 Published Online First 29 October 2019

\section{Check for updates}

(c) Author(s) (or their employer(s)) 2019. Re-use permitted under CC BY-NC. No commercial re-use. See rights and permissions. Published by BMJ.

To cite: Framke $\mathrm{E}$, Sørensen JK, Nordentoft M et al. Occup Environ Med 2019:76:895-900.

\section{ABSTRACT}

Objectives This study aimed to examine whether high emotional demands at work predict long-term sickness absence (LTSA) in the Danish workforce and whether associations differ by perceived and content-related emotional demands.

Methods We included 26410 individuals from the Work Environment and Health in Denmark Study, a nationwide sample of the Danish workforce. Emotional demands at work were measured with two items: one assessing perceived emotional demands (asking how often respondents were emotionally affected by work) and one assessing content-related emotional demands (frequency of contact with individuals in difficult situations). LTSA was register based and defined as spells of $\geq 6$ weeks. Respondents with LTSA during 2 years before baseline were excluded. Follow-up was 52 weeks. Using Cox regression, we estimated risk of LTSA per one-unit increase in emotional demands rated on a five-point scale.

Results During 22466 person-years, we identified 1002 LTSA cases. Both perceived (HR 1.20, 95\% Cl 1.12 to 1.28 ) and content-related emotional demands (HR 1.07, 95\% Cl 1.01 to 1.13) predicted risk of LTSA after adjustment for confounders. Further adjustment for baseline depressive symptoms substantially attenuated associations for perceived (HR 1.08, 95\% Cl 1.01 to 1.16) but not content-related emotional demands (HR 1.05, 95\% Cl 1.00 to 1.11). Individuals working in occupations with above-average values of both exposures had an increased risk of LTSA (HR 1.32, 95\% Cl 1.14 to 1.52 ) compared with individuals in all other job groups.

Conclusions Perceived and content-related emotional demands at work predicted LTSA, also after adjustment for baseline depressive symptoms, supporting the interpretation that high emotional demands may be hazardous to employee's health.

\section{INTRODUCTION}

Emotional demands at work concern aspects of work that require sustained emotional effort of employees. ${ }^{1}$ Examples of emotionally demanding work tasks are dealing with sick or dying patients, taking care of clients' emotional needs, responding
Key messages

What is already known about this subject?

- Whether high emotional demands at work are hazardous to employee's health is debated.

- Some studies found that emotional demands predicted long-term sickness absence (LTSA) and depression. Other studies raised concerns that these associations might have been affected by bias related to the measurement of emotional demands.

What are the new findings?

- Both perceived and content-related emotional demands at work predicted a higher risk of LTSA.

- Adjusting for the baseline psychological state of the individual attenuated the estimate for perceived emotional demands more than for content-related emotional demands, but estimates for both types of demands remained statistically significant.

How might this impact on policy or clinical practice in the foreseeable future?

- The results support the interpretation that high emotional demands contributes to a higher risk of LTSA.

- Workplaces may consider reducing emotional demands at work as a mean for ensuring or improving employee's health.

- Further research on work-related resources that may buffer the effect of emotional demands at work would provide insights on prevention possibilities.

to clients' sorrows and worries, and handling aggressive customers and clients. ${ }^{1-5}$

Whether a high level of emotional demands at work is hazardous to employee's health is debated. Whereas some studies found that emotional demands are associated with a higher risk of sickness absence, depressive symptoms and psychological distress, ${ }^{6-16}$ other studies raised concerns that the measurement of emotional demands may have biassed associations. $^{217}$ 
Previously, emotional demands have primarily been measured as perceived emotional demands, for example, with items like 'how often do you feel emotionally affected by work?'. This type of item may measure both characteristics of the work environment (ie, that work is emotionally demanding) and factors related to the emotional processing of the individual (ie, a psychological state of the individual). Thus, measuring emotional demands as perceived emotional demands mixes the exposure to emotional demands with the psychological state of the individual, and it remains unclear if subsequent outcomes are due to the exposure, the psychological state of the individual or both.

To address possible bias concerning the measurement of emotional demands, Vammen et al recently compared how perceived and content-related emotional demands were associated with risk of clinical depression. ${ }^{2}$ Unlike perceived emotional demands, items on content-related emotional demands do not to mix the environmental exposure and the individual's psychological state but focus on the content of the job task, such as dealing with others' grieves and worries. The study found that perceived emotional demands but not content-related emotional demands predicted risk of clinical depression, strengthening concerns about bias in studies examining perceived emotional demands. The study by Vammen et al was limited, although, by including only public sector employees, a relatively small study population of about 3000 participants and low statistical power with only 62 cases of depression at follow-up.

In this article, we investigate the association between different conceptualisations of emotional demands and risk of long-term sickness absence (LTSA) in a nationwide sample of the Danish workforce with more than 25000 employees. We chose LTSA as the outcome because LTSA is a valid indicator of ill-health, predicting both disability and mortality. ${ }^{18-20}$

In addition to measuring perceived and content-related emotional demands by self-report, we also measured these two types of emotional demands by job title, by aggregating selfreported emotional demands to the job group level. Measuring occupational exposures on the job group level instead of the individual level reduces reporting bias, although it might simultaneously increase risk of non-differential misclassification. ${ }^{21}$

We examined the prospective association between perceived and content-related emotional demands, measured on the individual level and the job group level, and risk of LTSA during a 1-year follow-up. We further examined if adjustment for participants' psychological state at baseline affected the strengths of the associations.

\section{METHODS}

\section{Study design and participants}

We analysed the prospective association between emotional demands at work with risk of LTSA by linking information on emotional demands, assessed with survey data from the Work Environment and Health in Denmark Study (WEHD), to register information on LTSA and covariates retrieved from nationwide registers. Time of follow-up was 52 weeks.

WEHD is a biennial survey of the work environment and health in Denmark from 2012 to 2020 . WEHD is based on a nationwide sample of Danish employees aged 18 to 64 years. For this study, we combined data from the 2014 and 2016 waves as these two waves included identical items for measuring emotional demands, whereas the wording in the 2012 wave was slightly different.

Figure 1 shows the flow chart towards the final study sample. In total, 67844 individuals were invited in the 2014 and 2016 waves of WEHD. Of these, 33544 responded to the questionnaire

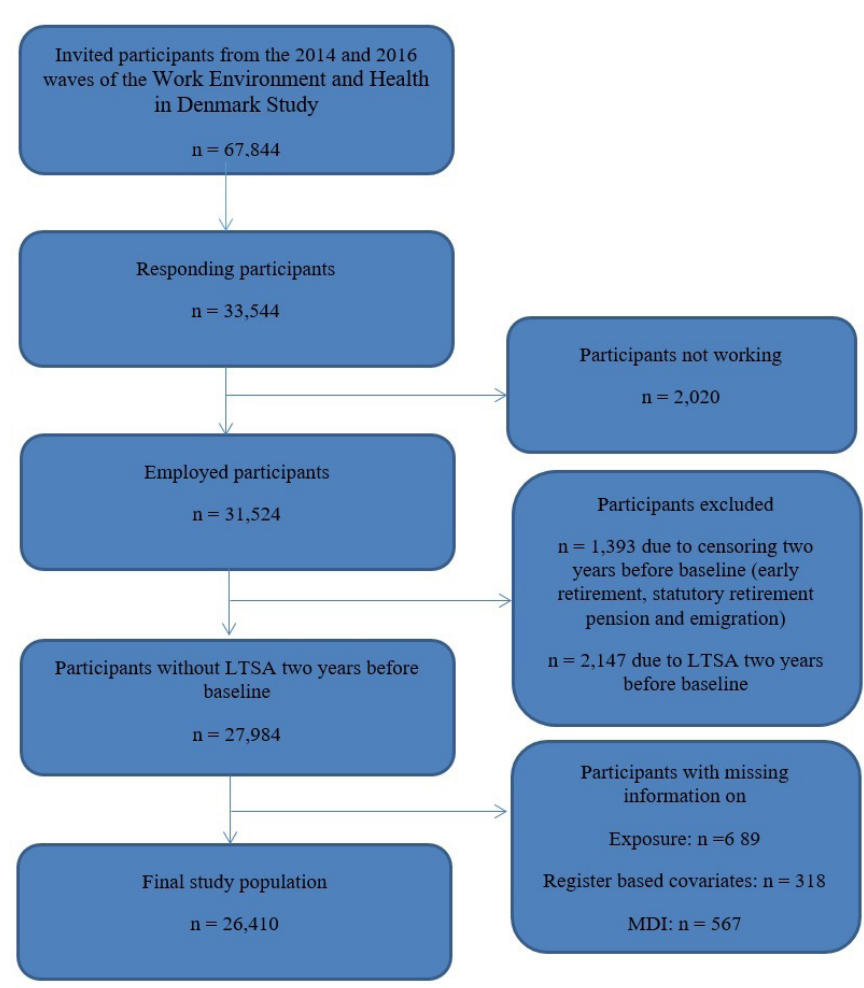

Figure 1 Flow chart towards the final study sample. LTSA, long-term sickness absence; MDI, Major Depression Inventory.

(49.4\%). We excluded 2020 respondents who were not working, 3540 with a history of LTSA or due to censoring (early retirement, statutory retirement pension and emigration) during 2 years before baseline, and finally, 1574 with missing information on exposures $(n=689)$ or potential confounders (register-based covariates: $\mathrm{n}=318$; depressive symptoms: $\mathrm{n}=567$ ), yielding a sample of 26410 participants. This sample was used for all analyses in this study.

\section{Measurement of emotional demands}

We measured emotional demands at work with two items: one item on perceived emotional demands and one item on content-related emotional demands. Perceived emotional demands were measured with the question: 'How often are you emotionally affected by your work?'. Content-related emotional demands was measured with the question: 'How often at work are you in contact with individuals in difficult situations (individuals who for example, are affected by serious disease, accident, grief, crisis, or social problems)?’. Both items were rated on a five-point scale (1: Never; 2: Seldom; 3: Sometimes; 4: Often; 5: Always).

We calculated a mean score of the two items (Cronbach's Alpha =0.56), resulting in a score from 1 to 5 , and we also used the two items as single measures. Further, we analysed the two single items as categorical variables. For this analysis, we collapsed the response categories 'Never' and 'Seldom' because of the low number of respondents in the category 'Never'.

\section{Measurement of LTSA}

We identified LTSA in the Danish Register for Evaluation of Marginalisation (DREAM) ${ }^{22}$ that includes weekly information on all social transfer payments in Denmark since 1991. Since 2012, sickness absence spells of 31 consecutive days or more are registered in DREAM. Sickness absence spells that lasts for 30 days or less are payed for and managed by the employer. 
Sickness absence spells $\geq 31$ days are partly reimbursed by the municipalities that manage the course of these longer sickness absence spells. Accordingly, we defined LTSA as $\geq 31$ consecutive days, corresponding to $\geq 6$ weeks in the DREAM register. For each participant, we measured the first episode of LTSA after the date of questionnaire completion and followed each individual for up to 52 weeks.

\section{Measurement of covariates}

As potential confounders we included age, sex, education, cohabitation, children living at home. We further adjusted for depressive symptoms at baseline as a measure of individuals' psychological state when responding to the questionnaire. All covariates have been associated with both emotional demands and LTSA in previous Danish studies, ${ }^{7324}$ and were therefore considered potential confounders. Information on these potential confounders was retrieved from Danish populationbased registers, ${ }^{25-28}$ except for depressive symptoms that were measured in WEHD.

Education was measured as the highest achieved education and categorised into four groups using the International Standard Classification of Education (ISCED) ${ }^{29}$ : primary and lower secondary (ISCED level 0-2); upper and post secondary (ISCED level 3-4); first stage tertiary (ISCED level 5); and second stage tertiary education (ISCED level 6). Cohabitation was measured as married/cohabiting yes versus no. Children living at home were categorised into three groups: no children; at least one child aged 0-7 years; at least one child aged 8-17 years (and no children younger than 8 years). Depressive symptoms were measured with the Major Depression Inventory (MDI) ${ }^{30}$ in the 2014 and 2016 waves of WEHD. The MDI consists of 10 items assessing the level of depressive symptoms during the last 2 weeks. Each item was measured on a scale ranging from 0 (the symptom has not been present at all) to 5 (the symptom has been present all of the time). The items were summed to an MDI score $(0-50)$, with higher scores indicating higher levels of depressive symptoms and included in the analyses as a continuous measure.

\section{Statistical analysis}

We analysed the association between emotional demands and subsequent LTSA by calculating HR and 95\% CI using Cox proportional hazards regression models. We followed each individual for up to 52 weeks from the date of completing the questionnaire until first episode of LTSA or censoring due to early retirement, disability retirement, statutory retirement pension, maternity leave, emigration, death or end of study, whichever came first. Information on reasons of censoring was retrieved from DREAM. ${ }^{22}$

First, we analysed the emotional demands mean score as a predictor for LTSA. Second, we analysed the separate scores for perceived and content-related emotional demands. Third, we analysed perceived and content-related emotional demands as categorical predictor variables.

We calculated unadjusted estimates and estimates adjusted for age, sex, education, cohabitation and children living at home (model 1), and further adjusted for baseline depressive symptoms (model 2).

Finally, we aggregated perceived and content-related emotional demands to the job group level by calculating the mean scores for each of the two items by job group defined by the three-digit level of DISCO-08, the Danish version of the International Standard Classification of Occupations' (ISCO)-08 system. Next, we assigned these mean scores to all individuals of the same job group. We plotted the job group mean scores of perceived and

\begin{tabular}{|c|c|c|c|c|}
\hline & $\mathrm{N}$ & $\%$ & Mean & SD \\
\hline Age & & & 45.3 & 11.4 \\
\hline \multicolumn{5}{|l|}{ Sex } \\
\hline Women & 13921 & 52.7 & & \\
\hline Men & 12489 & 47.3 & & \\
\hline \multicolumn{5}{|l|}{ Education } \\
\hline Primary and lower secondary education & 3751 & 14.2 & & \\
\hline Upper and post secondary education & 11244 & 42.6 & & \\
\hline First stage tertiary education & 7859 & 29.8 & & \\
\hline Second stage tertiary education & 3556 & 13.5 & & \\
\hline \multicolumn{5}{|l|}{ Cohabitation } \\
\hline Yes & 20524 & 77.7 & & \\
\hline No & 5886 & 22.3 & & \\
\hline \multicolumn{5}{|l|}{ Children living at home } \\
\hline No children & 14694 & 55.6 & & \\
\hline At least one child aged $0-7$ years & 5174 & 19.6 & & \\
\hline $\begin{array}{l}\text { At least one child aged } 8-17 \text { years (no } \\
\text { children younger than } 8 \text { years) }\end{array}$ & 6542 & 24.8 & & \\
\hline MDI & & & 8.1 & 7.4 \\
\hline Perceived emotional demands at work & & & 2.8 & 1.0 \\
\hline Never/seldom & 9525 & 36.1 & & \\
\hline Sometimes & 10567 & 40.0 & & \\
\hline Often & 5171 & 19.6 & & \\
\hline Always & 1147 & 4.3 & & \\
\hline Content-related emotional demands at work & & & 3.0 & 1.2 \\
\hline Never/seldom & 9947 & 37.7 & & \\
\hline Sometimes & 7368 & 27.9 & & \\
\hline Often & 5386 & 20.4 & & \\
\hline Always & 3709 & 14.0 & & \\
\hline
\end{tabular}

MDI, Major Depression Inventory.

content-related emotional demands against each other to visually display where each job group was located with regard to perceived and content-related emotional demands. Using the scatter plot, we identified job groups scoring above the mean on both perceived and content-related emotional demands and calculated the risk of LTSA among individuals in these job groups compared with individuals in all other job groups in the study population.

All analyses were conducted using SAS statistical software V.9.4.

\section{RESULTS}

\section{Characteristics of the study population}

Table 1 shows baseline characteristics of the study population. About half of the study population was women (52.7\%) and the mean age was 45.3 years $(S D=11.4)$. Most participants had upper and post secondary education as their highest completed education (42.6\%), were cohabiting (77.7\%) and had no children living at home (55.6\%). The mean MDI score was 8.1 $(\mathrm{SD}=7.4)$. About a quarter responded 'often' or 'always' to the item on perceived emotional demands (23.9\%), and about a third of the study population responded 'often' or 'always' to the item on content-related emotional demands (34.4\%).

\section{Individual-level emotional demands at work and subsequent risk of LTSA}

During 22466 person-years, we identified 1002 cases of LTSA (45 per 1000 person-years). Among participants experiencing an LTSA event during follow-up, the mean time from baseline to event was 24 weeks. 
Table 2 Associations of emotional demands at work at baseline with risk of long-term sickness absence during 52 weeks of follow-up

\begin{tabular}{|c|c|c|c|c|c|c|c|c|c|}
\hline & \multirow[b]{2}{*}{$\mathbf{n}$} & \multirow[b]{2}{*}{ Cases } & \multirow{2}{*}{$\begin{array}{l}\text { Cases per } \\
1000 \text { PY }\end{array}$} & \multicolumn{2}{|c|}{ Unadjusted } & \multicolumn{2}{|c|}{ Model 1} & \multicolumn{2}{|c|}{ Model 2} \\
\hline & & & & HR & $95 \% \mathrm{Cl}$ & HR & $95 \% \mathrm{Cl}$ & HR & $95 \% \mathrm{Cl}$ \\
\hline \multicolumn{10}{|c|}{ Emotional demands score } \\
\hline One-unit increase & 26410 & 1002 & 45 & 1.27 & 1.19 to 1.36 & 1.18 & 1.10 to 1.27 & 1.10 & 1.02 to 1.18 \\
\hline \multicolumn{10}{|c|}{ Perceived emotional demands at work } \\
\hline One-unit increase & 26410 & 1002 & 45 & 1.25 & 1.17 to 1.33 & 1.20 & 1.12 to 1.28 & 1.08 & 1.01 to 1.16 \\
\hline Never/seldom & 9525 & 282 & 34 & 1.00 & & 1.00 & & 1.00 & \\
\hline Sometimes & 10567 & 394 & 44 & 1.27 & 1.09 to 1.48 & 1.15 & 0.98 to 1.35 & 1.06 & 0.91 to 1.25 \\
\hline Often & 5171 & 262 & 60 & 1.74 & 1.47 to 2.06 & 1.55 & 1.30 to 1.84 & 1.24 & 1.04 to 1.48 \\
\hline Always & 1147 & 64 & 67 & 1.93 & 1.47 to 2.53 & 1.70 & 1.30 to 2.24 & 1.25 & 0.94 to 1.65 \\
\hline \multicolumn{10}{|c|}{ Content-related emotional demands at work } \\
\hline One-unit increase & 26410 & 1002 & 45 & 1.14 & 1.08 to 1.19 & 1.07 & 1.01 to 1.13 & 1.05 & 1.00 to 1.11 \\
\hline Never/seldom & 9947 & 325 & 38 & 1.00 & & 1.00 & & 1.00 & \\
\hline Sometimes & 7368 & 273 & 43 & 1.14 & 0.97 to 1.34 & 1.03 & 0.87 to 1.21 & 1.02 & 0.87 to 1.20 \\
\hline Often & 5386 & 218 & 48 & 1.25 & 1.06 to 1.49 & 1.07 & 0.89 to 1.27 & 1.02 & 0.86 to 1.22 \\
\hline Always & 3709 & 186 & 60 & 1.56 & 1.30 to 1.87 & 1.28 & 1.07 to 1.55 & 1.22 & 1.01 to 1.47 \\
\hline
\end{tabular}

Model 1: Age, sex, education, cohabitation and children living at home.

Model 2: Age, sex, education, cohabitation, children living at home and MDI.

PY, person-years.

Table 2 shows the unadjusted and adjusted estimates and 95\% CI of the prospective association between emotional demands at work at baseline and risk of LTSA. In the unadjusted model, a one-unit increase in the emotional demands score predicted risk of LTSA with an HR of 1.27 (95\% CI 1.19 to 1.36). The estimate attenuated after adjustment for age, sex, education, cohabitation and children living at home (HR 1.18, 95\% CI 1.10 to 1.27 , model 1) and further adjustment for depressive symptoms (HR 1.10, 95\% CI 1.02 to 1.18 , model 2) but remained statistically significant.

When we analysed the scores for perceived and content-related emotional demands separately, we found that both scores predicted risk of LTSA after adjustment for age, sex, education, cohabitation and children living at home, with perceived emotional demands showing stronger associations (HR 1.20, 95\% CI 1.12 to 1.28 ) than content-related emotional demands (HR 1.07, 95\% CI 1.01 to 1.13). After further adjustment for depressive symptoms, the estimate for perceived emotional demands attenuated substantially (HR 1.08, 95\% CI 1.01 to 1.16), whereas the estimate for contentrelated emotional demands changed only marginally (HR 1.05, 95\% CI 1.00 to 1.11 ).

In supplementary analyses, we repeated models 1 and 2 for the emotional demands score without excluding individuals with LTSA during the 2 years before baseline from the study population, but while adjusting for LTSA during the 2 years before baseline in both models. Results were similar to the results of the main analysis (results not shown).

\section{Content-related and perceived emotional demands by job group and risk of LTSA}

Figure 2 shows a scatter plot of the mean scores of the two emotional demands items by job group according to the three-digit level of DISCO-08 occupational classification system. There was a positive correlation $\left(r^{2}=0.35\right)$ between perceived emotional demands and content-related emotional demands. Job groups that scored above the mean on both measures of emotional demands were, for example, primary school and early childhood teachers (234), other teaching professionals (235), medical doctors (221), nursing and midwifery professionals (222), and personal care workers in health services (532) (see online supplementary appendix 1 for the scores for each job group).
Table 3 shows the results from the analysis of risk of LTSA among individuals working in job groups that scored above the mean on both perceived and content-related emotional demands compared with individuals working in all other job groups. The HR was 1.32 (95\% CI 1.14 to 1.52) in the most adjusted model.

\section{DISCUSSION}

This study of a nationwide sample of 26410 employees in Denmark showed that emotional demands, measured with a global score, a perceived emotional demands score and a content-related emotional demands score, predicted a higher risk of LTSA during a 1-year follow-up in the most-adjusted model that included adjustment for the psychological state of the individual at baseline. The adjustment for the psychological state attenuated the estimate for perceived emotional demands more than for content-related emotional demands.

Further analyses showed that individuals working in job groups that scored above the mean on both perceived and content-related emotional demands compared with individuals

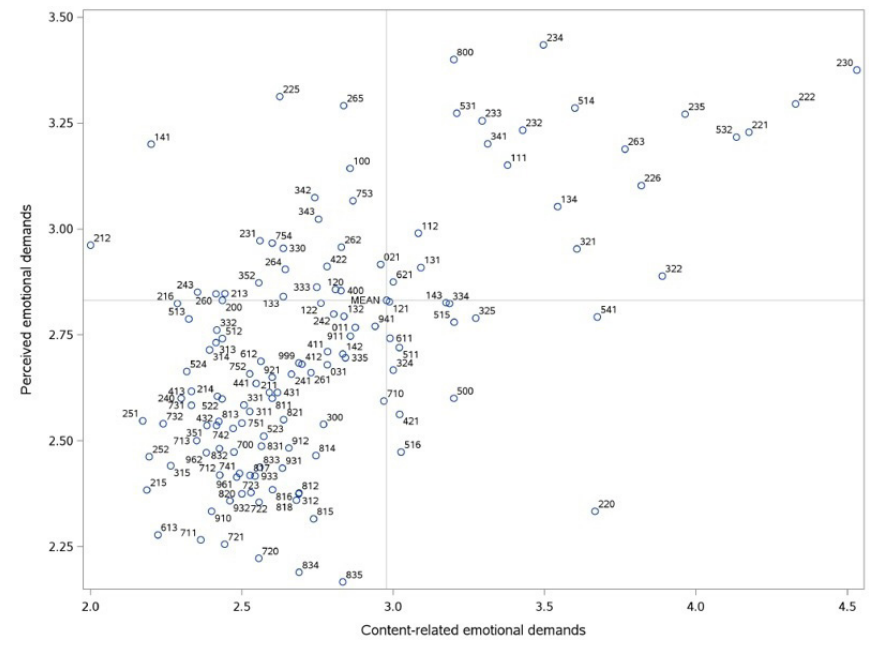

Figure 2 Job group mean scores of perceived and content-related emotional demands at work items by job group according to the three-digit level of DISC0-08 occupational classification system. 
Table 3 Risk of long-term sickness absence among individuals working in job groups characterised by both high perceived and high contentrelated emotional demands at work compared with individuals working in all other job groups

\begin{tabular}{|c|c|c|c|c|c|c|c|c|c|}
\hline & \multirow[b]{2}{*}{$\mathrm{n}$} & \multirow[b]{2}{*}{ Cases } & \multirow{2}{*}{$\begin{array}{l}\text { Cases per } \\
1000 \mathrm{PY}\end{array}$} & \multicolumn{2}{|c|}{ Unadjusted } & \multicolumn{2}{|c|}{ Model 1} & \multicolumn{2}{|c|}{ Model 2} \\
\hline & & & & HR & $95 \% \mathrm{Cl}$ & HR & $95 \% \mathrm{Cl}$ & HR & $95 \% \mathrm{Cl}$ \\
\hline \multicolumn{10}{|l|}{ Job group level combined measure } \\
\hline All other combinations & 18340 & 609 & 39 & 1.00 & & 1.00 & & 1.00 & \\
\hline High perceived and high content-related & 8070 & 393 & 58 & 1.49 & 1.31 to 1.69 & 1.32 & 1.14 to 1.52 & 1.32 & 1.14 to 1.52 \\
\hline
\end{tabular}

Model 1: Age, sex, education, cohabitation and children living at home.

Model 2: Age, sex, education, cohabitation, children living at home and MDI.

MDI, Major Depression Inventory; PY, person-years.

working in all other job groups had a higher risk of LTSA and that the estimate did not change after adjustment for the psychological state of the individual.

This study contributes with new insight into the potential effects of high emotional demands for employees' risk of LTSA by using separate measures of perceived and content-related emotional demands in a nationwide cohort, by adjusting for the baseline psychological state of the individual and by aggregating data to the job group level to circumvent reporting bias. A previous study by Vammen et $a l^{2}$ concluded that perceived emotional demands, but not the less reporting bias prone measure content-related emotional demands, were a risk factor for clinical depression. Therefore, the authors suggested that associations found in previous studies and in their own study may be explained by the individuals' perception and not by the actual content of emotionally demanding work tasks. Consequently, the findings by Vammen et al did not support a causal effect of emotional demands at work and employee's health. The present study, however, suggests that both perceived and content-related emotional demands are a risk factor for LTSA, a strong predictor of morbidity and mortality. Further, our findings suggest that the association between emotional demands and ill-health can only partly, but not completely, be attributable to the psychological state of the individual at the time when individuals are reporting their emotional demands exposure. This interpretation is further supported by the results from the analyses showing that job group level averaged exposure to the combination of both types of emotional demands predicted individual-level risk of LTSA.

Results from observational studies suggest that good leadership did not substantially buffer the negative effects of emotional demands at work on employee's health, ${ }^{31}$ that work-related goal attainment moderated the negative effect of effort in emotion work on employee well-being ${ }^{32}$ and that experiencing one's work as emotionally enriching and meaningful reduced the effect of emotional demands on exhaustion. ${ }^{33}$

\section{Strengths and limitations}

The strengths of this study include the large cohort consisting of 26410 individuals in a nationwide sample of the Danish workforce in the age group 18-64 years and the use of outcome and covariate measurements from Danish population-based registers. As participants were followed-up in registers, attrition during follow-up was minimal. A further strength is that we addressed possible reporting bias by adjusting for baseline depressive symptoms as a proxy measure for participants' psychological state and by aggregating the individual-level exposures to the job group level in additional analyses.

Some limitations need to be mentioned. First, we only had two single item measures available for emotional demands. By measuring our two exposure variables with only one item each, we likely have measured limited aspects of perceived and content-related emotional demands. The content-related item focused on frequency of contact with individuals in difficult situations, where difficult situations were elaborated with examples like being in contact with individuals who, for example, are affected by serious disease, accident, grief, crisis or social problems. These are rather serious situations and it is possible that we did not capture less serious forms of content-related emotional demands, such as having to care for emotional needs of others (eg, nursing home residents), helping others solving conflicts (eg, younger pupils in primary school) or handling rude customers (eg, in supermarkets). Our study would have benefitted from including more items to study different aspects of the concept of content-related emotional demands. Second, while attrition during follow-up was minimal due to register-based follow-up with full coverage, the baseline response rate of about $50 \%$ raises concerns about selective responding. Analyses of Danish national work environment surveys have shown that response rates tend to be lower among men, individuals of younger age and individuals of lower education, ${ }^{3435}$ and we adjusted for these key sociodemographic variables in our analyses. Further, it is possible that risk of sickness absence was different for baseline responders and nonresponders; however, we could not examine this, as we did not have information on sickness absence rates of non-responders. Third, it is possible that some unmeasured psychological characteristics may have been related to selection into occupations with high emotional demands and higher risk of sickness absence and therefore may have biassed our results. ${ }^{11}$ Excluding individuals with LTSA during the 2 years before baseline and adjusting for baseline depressive symptoms may partly, but not completely, have accounted for this bias. Fourth, the administrative registers in Denmark that we can use for research purposes do not include information on the cause of LTSA. Therefore, we do not know whether the 1002 LTSA episodes in this study were due to mental disorders, somatic diseases or injuries. Fifth, although long-term sickness absence is closely related to both morbidity and mortality and, thus, can be regarded as an indicator of ill-health, ${ }^{18-20}$ incident sickness absence is likely not exclusively determined by illhealth, but probably also by other factors, such as sickness absence legislations and practices, financial aspects or general attitudes at workplaces towards sickness absence. ${ }^{36}$ Future research may investigate whether these factors might confound or moderate the association between emotional demands at work and risk of LTSA. Finally, a sixth limitation is related to generalisability. As we conducted our study in a large sample of employed Danish residents from a wide range of job groups, we consider our results as generalisable to the Danish workforce. However, our results may not be generalisable to workforces in other countries, as national sickness absence legislations could influence the associations between working conditions and LTSA. Further studies on emotional demands at work and LTSA in other countries, particularly other than Nordic countries, are encouraged. 


\section{CONCLUSION}

Perceived, content-related and job group aggregated levels of emotional demands at work all predicted risk of LTSA. Adjustment for the baseline psychological state of the individual measured by depressive symptoms affected the estimate for perceived emotional demands more than the estimate for content-related emotional demands but associations remained statistically significant in all analyses. This study therefore supports the notion that high emotional demands at work are a risk factor of LTSA. As LTSA is a valid indicator of ill-health, we conclude that high emotional demands at work may be hazardous to employee's health.

Correction notice This article has been corrected since it published Online First.

Contributors EF, JKS, IEHM and RR contributed to the conception of the study, and all authors contributed to the interpretation of data. JKS and EF conducted the data analysis. EF drafted the manuscript, and all authors critically revised it and approved the final version.

Funding This study was funded by the Danish Work Environment Research Fund (grant numbers 27-2017-03 and 10-2016-02).

Competing interests None declared.

\section{Patient consent for publication Not required.}

Ethics approval The National Committee on Health Research Ethics. The study was approved by The Danish Data Protection Agency through the joint notification of the National Research Centre for the Working Environment (no. 2015-57-0074). All data are stored in a protected server environment hosted by Statistics Denmark.

Provenance and peer review Not commissioned; externally peer reviewed.

Data availability statement Data may be obtained from a third party and are not publicly available.

Open access This is an open access article distributed in accordance with the Creative Commons Attribution Non Commercial (CC BY-NC 4.0) license, which permits others to distribute, remix, adapt, build upon this work non-commercially, and license their derivative works on different terms, provided the original work is properly cited, appropriate credit is given, any changes made indicated, and the use is non-commercial. See: http://creativecommons.org/licenses/by-nc/4.0/.

\section{ORCID iDs}

Elisabeth Framke http://orcid.org/0000-0002-5702-3954

Anne Helene Garde http://orcid.org/0000-0002-1553-2291

Jacob Pedersen http://orcid.org/0000-0003-4429-3485

Ida E H Madsen http://orcid.org/0000-0003-3635-3900

Reiner Rugulies http://orcid.org/0000-0002-7752-131X

\section{REFERENCES}

1 Söderfeldt Met al. Quantitative versus emotional demands among Swedish human service employees: moderating effects of job control and social support. Inter J Stress Manag 2004;11.

2 Vammen MA, Mikkelsen S, Hansen Åse Marie, et al. Emotional demands at work and the risk of clinical depression: a longitudinal study in the Danish public sector. J Occup Environ Med 2016:58:994-1001.

3 Söderfeldt B, Söderfeldt M, Muntaner C, et al. Psychosocial work environment in human service organizations: a conceptual analysis and development of the demandcontrol model. Soc Sci Med 1996;42:1217-26.

4 Zapf D, Vogt C, Seifert C, et al. Emotion work as a source of stress: the concept and development of an instrument. European Journal of Work and Organizational Psychology 1999:8:371-400.

5 Zapf D, Seifert C, Schmutte B, et al. Emotion work and job stressors and their effects on burnout. Psychol Health 2001;16:527-45.

6 Lund T, Labriola M, Christensen KB, et al. Psychosocial work environment exposures as risk factors for long-term sickness absence among Danish employees: results from DWECS/DREAM. J Occup Environ Med 2005;47:1141-7.

7 Rugulies R, Aust B, Pejtersen JH. Do psychosocial work environment factors measured with scales from the Copenhagen psychosocial questionnaire predict registerbased sickness absence of 3 weeks or more in Denmark? Scand J Public Health 2010;38:42-50.

8 Rugulies R, Christensen KB, Borritz M, et al. The contribution of the psychosocial work environment to sickness absence in human service workers: results of a 3-year followup study. Work \& Stress 2007;21:293-311.

9 Roelen C, Thorsen S, Heymans M, et al. Development and validation of a prediction model for long-term sickness absence based on occupational health survey variables. Disabil Rehabil 2018;40:168-75.
10 Aagestad C, Johannessen HA, Tynes T, et al. Work-Related psychosocial risk factors for long-term sick leave: a prospective study of the general working population in Norway. J Occup Environ Med 2014;56:787-93.

11 Madsen IEH, Diderichsen F, Burr H, et al. Person-related work and incident use of antidepressants: relations and mediating factors from the Danish work environment cohort study. Scand J Work Environ Health 2010;36:435-44.

12 Magnusson Hanson LL, Madsen IEH, Westerlund H, et al. Antidepressant use and associations with psychosocial work characteristics. A comparative study of Swedish and Danish gainfully employed. J Affect Disord 2013;149:38-45.

13 Andrea $\mathrm{H}$, Bültmann U, van Amelsvoort LGPM, et al. The incidence of anxiety and depression among employees-the role of psychosocial work characteristics. Depress Anxiety 2009;26:1040-8.

14 Slany C, Schütte S, Chastang J-F, et al. Psychosocial work factors and long sickness absence in Europe. Int J Occup Environ Health 2014;20:16-25.

15 Diestel S, Schmidt K-H. Costs of simultaneous coping with emotional dissonance and self-control demands at work: results from two German samples. J App/ Psychol 2011:96:643-53.

16 Dollard MF, Tuckey MR, Dormann C. Psychosocial safety climate moderates the job demand-resource interaction in predicting Workgroup distress. Accid Anal Prev 2012;45:694-704

17 Jakobsen LM, Jorgensen AFB, Thomsen BL, et al. Emotion work within eldercare and depressive symptoms: a cross-sectional multi-level study assessing the association between externally observed emotion work and self-reported depressive symptoms among Danish eldercare workers. Int J Nurs Stud 2016:62:183-92.

18 Kivimäki M, Head J, Ferrie JE. Sickness absence as a global measure of health: evidence from mortality in the Whitehall II prospective cohort study. Br Med J 2003;327.

19 Kivimäki Met al. Sickness absence as a risk marker of future disability pension: the 10-town study. J Epidemiol Community Health 2004;58:710-1.

20 Melchior M, Ferrie JE, Alexanderson K, et al. Using sickness absence records to predict future depression in a working population: prospective findings from the GAZEL cohort. Am J Public Health 2009;99:1417-22.

21 Madsen IEH, Gupta N, Budtz-Jørgensen E, et al. Physical work demands and psychosocial working conditions as predictors of musculoskeletal pain: a cohort study comparing self-reported and job exposure matrix measurements. Occup Environ Med 2018;75:752-8.

22 Burr H, Pedersen J, Hansen JV. Work environment as predictor of long-term sickness absence: linkage of self-reported DWECS data with the DREAM register. Scand J Public Health 2011:39:147-52.

23 Nielsen ML, Rugulies R, Christensen KB, et al. Psychosocial work environment predictors of short and long spells of registered sickness absence during a 2-year follow up. J Occup Environ Med 2006;48:591-8.

24 Hjarsbech PU, Andersen RV, Christensen KB, et al. Clinical and non-clinical depressive symptoms and risk of long-term sickness absence among female employees in the Danish eldercare sector. J Affect Disord 2011;129:87-93.

25 Pedersen CB. The Danish civil registration system. Scand J Public Health 2011;39:22-5

26 Jensen VM, Rasmussen AW, Registers DE. Danish education registers. Scand J Public Health 2011;39:91-4

27 Statistics Denmark. Documentation of statistics for households, families and children, 2017. Available: https://www.dst.dk/en/Statistik/dokumentation/documentationofstat stics/households-families-and-children

28 Statistics Denmark. Documentation of statistics for the population, 2018. Available: https://www.dst.dk/en/Statistik/dokumentation/documentationofstatistics/thepopulation

29 The United Nations Educational Scientific and Cultural Organization (UNESCO). International standard classification of education (ISCED), 2018. Available: http://uis. unesco.org/en/topic/international-standard-classification-education-isced

30 Bech $\mathrm{P}$, Rasmussen N-A, Olsen LR, et al. The sensitivity and specificity of the major depression inventory, using the present state examination as the index of diagnostic validity. J Affect Disord 2001;66:159-64.

31 Madsen IEH, Hanson LLM, Rugulies R, et al. Does good leadership buffer effects of high emotional demands at work on risk of antidepressant treatment? A prospective study from two Nordic countries. Soc Psychiatry Psychiatr Epidemiol 2014;49:1209-18.

32 Wong E, Tschan F, Semmer NK. Effort in emotion work and well-being: the role of goal attainment. Emotion 2017;17:67-77

33 Vammen MA, Mikkelsen S, Forman JL, et al. Emotional demands and exhaustion: cross-sectional and longitudinal associations in a cohort of Danish public sector employees. Int Arch Occup Environ Health 2019:92:639-50.

34 Johnsen NF, Thomsen BL, Hansen JV, et al. Job type and other socio-demographic factors associated with participation in a national, cross-sectional study of Danish employees. BMJ Open 2019;9:e027056.

35 Feveile $\mathrm{H}$, Olsen O, Burr $\mathrm{H}$, et al. Danish work environment cohort study 2005: from idea to sampling design. Statistics in Transition 2007:8:441-58.

36 Allebeck P, Mastekaasa A. Swedish Council on Technology Assessment in Health Care (SBU). Chapter 5. Risk factors for sick leave - general studies. Scand J Public Health 2004;63. 